\title{
A Procedure for Placing Shunt Reactors in High-Voltage Networks and Justification of its Efficiency
}

\author{
A.M.Hashimov, H.B.Guliyev*, A.R.Babayeva, F.Sh.Ibrahimov
}

Azerbaijan Research and Design-Prospecting Institute of Power Engineering, Baku, Azerbaijan

\begin{abstract}
In recent years, the controlled shunt reactor (CSR), a type of FACTS device, has been widely used to regulate voltage and reactive power flows in the highvoltage electrical network. The selection of location and the determination of the law of CSR control under the stochastically variable operation of high-voltage power transmission lines are associated with numerous technical and economic factors. At the same time, one should take into account such limiting conditions as ease of use, performance, purpose, and location in the system, as well as the time of commissioning. In the proposed procedure, these factors are considered as fuzzy constraints.
\end{abstract}

The paper proposes a procedure for CSR placement in the $330 \mathrm{kV}$ electrical network of the "Azerenergy" system for control of reactive power flows, given the mentioned fuzzy constraints. The obtained simulation results demonstrate the advantage of the proposed procedure. The computational experiments confirm the CSR efficiency.

Index Terms - Energy systems, FACTS device, power balance, Fuzzy Logic, active and reactive power flow control.

\section{INTRODUCTION}

Nowadays, the power industries in various countries attach great importance to the creation of controlled or flexible power lines, which are part of Smart Grid with FACTS devices [1-3]. Optimal control of operating conditions of such power systems requires highly efficient means of control of both active and reactive power flows.

\footnotetext{
${ }^{*}$ Corresponding author.

E-mail: huseyngulu@mail.ru
}

http://dx.doi.org/10.38028/esr.2020.01.0007

Received Month 00, 2020. Revised Month 00, 2020.

Accepted Month 00, 2020. Available online Month 00, 2020.

This is an open access article under a Creative Commons Attribution-NonCommercial 4.0 International License.

(C) 2020 ESI SB RAS and authors. All rights reserved.
In recent decades, apart from generators, synchronous and static compensators, switching reactors and capacitor banks, new facilities - controlled shunt reactors (CSR) have been widely used to regulate voltage and reactive power [4-6]. The economic analysis has shown that without CSR additional power losses are so high that despite the available expensive equipment, the CSR installation pays back in less than 5 years $[7,8]$. There is still a problem of eliminating excessive reactive power generated under the minimum load conditions in most power grids. The main reason for this excess is that the charging power in 330 $\mathrm{kV}$ lines is higher than the losses due to reactive power in them, and this can cause an increase in voltage to a level dangerous for the line insulation.

Conventional methods and means used today to eliminate surplus reactive power are not effective enough and should be replaced by more advanced ones. In this regard, $330 \mathrm{kV}$ CSR is preferable. The relationship between reactive power losses in the networks and their charging power is not constant and varies in a wide range. Therefore, to ensure the reactive power balance, the CSR power must be controlled in a broad range [9].

The selection of power and site for CSR installation, as well as the determination of the law of control, and damping changes in the operation of transmission lines are associated with numerous economic and technical factors. These factors as well as the CSR characteristics affect power losses in the entire power transmission line, the stability of the operation, voltage regulation within the predetermined limits at various values of transmitted power, and overvoltage in individual components of the power transmission line. The selection of CSR should also take into account other factors. These are the convenience of the place for the CSR installation at a given point of the network in terms of operation, performance, technical and economic indices. Therefore, given various uncertain factors for different networks, an acceptable option for the selection and placement of compensating devices is determined.

The authors of [9] show that controlled devices for reactive power compensation, voltage, and power flow regulation should be installed at electrical network facilities if it is necessary to reduce voltage deviations to 
acceptable levels, increase the transfer capability of power transmission lines (PTL), and reduce losses in electrical networks of power systems. The site, type, and power of the controlled devices should be chosen based on the technical and economic calculations. The economic effect of the use of the controlled devices depends on their cost, damage caused by the accelerated deterioration of equipment due to voltage deviation, cost of losses, and cost of additionally obtained transfer capability of PTL.

Therefore, the determination of an optimal option when selecting compensating facilities in the context of numerous influencing factors and specified practical cases arrives at solving a multi-purpose problem with constraints. However, solving this problem without modern mathematical technologies is extremely complicated.

The issue of CSR placement in high-voltage electrical networks is considered in [10]. Here, the criteria for the decrease in the active power losses and voltage in the network due to the CSR effect are taken as a basis. However, the location of substations in the system, years of operation, scheme, etc. are not taken into account.

A procedure for determining the location of shunt reactors in $330-500 \mathrm{kV}$ electrical networks based on the criteria of short-circuit power, voltage deviation, and reactor power change is given in [11]. Although this procedure provides the necessary methodological support for determining a site for the reactors, it does not allow assessing the level of mistake of not considering the above factors.

A new criterion is proposed in [12] for choosing the location of shunt reactors to improve the transient characteristics of power systems under minimum load conditions, however, the above important factors, affecting the calculation results, are not taken into account.

The focus of the present paper is on the selection and placement of $330 \mathrm{kV}$ controlled shunt reactors based on the studies conducted on a real power system scheme.

\section{CSR PLACEMENT AT 330 KV NODES OF POWER SYSTEM}

A special procedure can be used to place the reactor in the power system. To determine the criteria for the selection of the most efficient CSR locations, it is necessary to analyze their impact on two important indices of the power system operation. These indices are the values of absolute and relative reduction in voltage levels at various points of the network before and after the reactor installation, as well as the values of losses in the network. Calculations should be carried out for the minimum load conditions so that the voltage levels at the observed points of the network reach the maximum possible value. Obviously, under these conditions, the reactor power should be maximal. Therefore, during the comparative calculations, the CSR power is assumed to be equal to the reactor rated power for all nodes.

Placement of one CSR at individual substations will affect differently the average voltage level at $330 \mathrm{kV}$ nodes of the power system and the total loss in the networks. The CSR installation at any substation will lower the voltage level both at this substation (mostly) and at other substations. Therefore, the average reduction in voltage can be assumed as the main technical efficiency index of the reactor installation. Another important index is the reduction in power losses in the networks. It is worth noting that with the installation of the single CSR, in contrast to voltage, the power loss can both increase and decrease.

In view of the above-mentioned, the mean absolute $\delta U_{o r}$, mean relative $\delta \bar{U}_{o r}$ voltage reduction, and, accordingly, the absolute $\delta P_{\Sigma}$ and relative $\delta \bar{P}_{\Sigma}$ total power loss reduction can be assumed as a special technical efficiency index of the reactor installation. These magnitudes can be determined through multivariate calculations of steady states with the alternate CSR placement at different substations. Moreover, for a comprehensive assessment of

Table 1. Efficiency index values for $330 \mathrm{kv}$ nodes of the power system.

\begin{tabular}{|c|c|c|c|c|c|c|c|c|c|}
\hline \multirow{2}{*}{ Node No. } & \multirow{2}{*}{ Node name } & \multicolumn{2}{|c|}{ Voltage, $\mathrm{kV}$} & \multirow{2}{*}{ 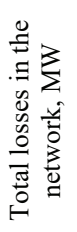 } & \multicolumn{2}{|c|}{$\begin{array}{c}\text { Absolute and } \\
\text { relative decrease } \\
\text { in total losses }\end{array}$} & \multicolumn{2}{|c|}{$\begin{array}{c}\text { Average absolute } \\
\text { and relative } \\
\text { voltage }\end{array}$} & \multirow{2}{*}{$\begin{array}{c}\text { Efficiency } \\
\text { index, } \\
E_{e f}\end{array}$} \\
\hline & & $\begin{array}{l}\text { Bus voltage before } \\
\text { CSR connection }\end{array}$ & $\begin{array}{l}\text { Average voltage } \\
\text { after CSR } \\
\text { connection }\end{array}$ & & MW & $\%$ & $\mathrm{kV}$ & $\%$ & \\
\hline 39 & Absheron 330 & 344.38 & 334.23 & 14.5 & 0.7 & 4.61 & 3.60 & 1.07 & 4.912 \\
\hline 201 & Janub PP & 346.53 & 334.66 & 14.6 & 0.6 & 3.94 & 3.17 & 0.94 & 3.701 \\
\hline 101 & Yashma 330 & 342.18 & 333.96 & 14.9 & 0.3 & 1.97 & 3.87 & 1.15 & 2.261 \\
\hline 601 & Mini HPP & 339.44 & 335.55 & 14.7 & 0.5 & 3.29 & 2.41 & 0.71 & 2.349 \\
\hline 651 & AzES330 & 339.23 & 335.55 & 14.7 & 0.5 & 3.29 & 2.28 & 0.68 & 2.219 \\
\hline 400 & Goranboy SG & 338.76 & 334.91 & 14.9 & 0.3 & 1.97 & 2.92 & 0.86 & 1.704 \\
\hline 333 & Agdjabedi330 & 342.64 & 333.78 & 15.0 & 0.2 & 1.32 & 4.05 & 1.19 & 1.577 \\
\hline 280 & Imishli 330 & 344.27 & 333.86 & 15.0 & 0.2 & 1.32 & 3.97 & 1.18 & 1.548 \\
\hline 801 & Khachmaz330 & 343.43 & 333.99 & 15.0 & 0.2 & 1.32 & 3.84 & 1.14 & 1.497 \\
\hline 411 & Shamkir HPP & 331.01 & 336.13 & 15.4 & -0.2 & -1.32 & 1.70 & 0.50 & -0.663 \\
\hline 401 & Gandja330 & 329.82 & 335.79 & 15.5 & -0.3 & -1.97 & 2.04 & 0.60 & -1.190 \\
\hline 456 & Samukh 330 & 328.74 & 335.98 & 15.6 & -0.4 & -2.63 & 1.85 & 0.55 & -1.443 \\
\hline 457 & GAZ 330 & 328.28 & 335.89 & 15.8 & -0.6 & -3.95 & 1.94 & 0.58 & -2.269 \\
\hline 502 & Agstafa 330 & 330.89 & 335.25 & 15.9 & -0.7 & -4.61 & 2.58 & 0.76 & -3.516 \\
\hline
\end{tabular}


technical and economic efficiency of the CSR application, the resulting efficiency index $E_{e f, \Sigma}$ was proposed, which is expressed as follows:

$$
E_{e f, \Sigma}=\delta \bar{U}_{o r} \cdot \delta \bar{P}_{\Sigma}
$$

The value of this index can be used to assess the comparative efficiency of the CSR installation at different points of the network. It should be noted that in the case where the CSR placement has the same effect on the average voltage level (it always declines), it has a double effect on the level of reactor losses.

Thus, in this case, the loss can both increase (useful effect) and decrease (useless effect). The comparison and sequencing of substations according to the $E_{e f, \Sigma}$ index will have an effect at its positive values. In other words, the sites for the CSR installation should be selected among the nodes with $E_{e f, \Sigma}>0$. In addition, other factors should be taken into account, especially the time of commissioning of substations, the availability of a place for CSR installation, and the possibility of reactive power flows from neighboring power systems.

The values of special and resultant efficiency indices for the $330 \mathrm{kV}$ nodes of the power system (initial loss of 15.2 MW) are given in Table 1 . The nodes are arranged in decreasing order of the $E_{e f, \Sigma}$ index values.

As seen in the Table, the $E_{e f, \Sigma}$ value is positive only for 9 nodes of the considered 14, and the sites for reactor installation should be selected between the nodes just with this value $E_{e f, \Sigma}>0$. In this case, in addition to the condition $E_{e f, \Sigma}>0$, as noted above, other factors should be taken into account (the periods of commissioning of substations, the availability of sites for the SR installation, the technical capabilities of the switchgear schematic diagram, etc.).

\section{CONSIDERATION OF CONSTRAINTS FOR CSR PLACEMENT}

The other 5 factors influencing the selection of a site for the CSR installation were taken into account as fuzzy constraints: the substation commissioning time; the substation operation period; the availability of the site for installation; the possibility of an electrical wiring diagram; and the substation location in the system. The Gaussian Z-shape and S-shape membership functions were assumed for linguistic variables [10-13].

The Gaussian membership function is

$$
\mu_{k i}(x)=\exp \left(\frac{-\left(x_{i}-m_{k i}\right)}{2 \sigma_{k i}{ }^{2}}\right), i=\overline{1, n} \quad k=\overline{1, m}
$$

where $m$ is the coordinate of the maximum; $\sigma$ is the concentration ratio.

$z m f$ and $s m f$ are the membership functions

$$
\mu_{k i}(x)=\left\{\begin{array}{lr}
1, & x_{i} \leq a_{k i} \\
\text { non-linear approximation, } a_{k i}<x_{i} & <b_{k i} \\
0, & x_{i} \geq b_{k i}
\end{array}\right.
$$

where $m$ is the coordinate of the maximum; is concentration ratio; $a, d$ is a fuzzy set carrier; $b, c$ is a fuzzy set kernel, $\mu_{A, i}(x): X_{i} \rightarrow[0,1]$.

For each linguistic variable the fuzzy constraints are introduced on:

the efficiency index:

$$
\mu_{E F}\left(x_{1}\right)=\left\{\begin{array}{lll}
P B, & \text { if } & x_{1}>3 \\
P S, & \text { if } & 0 \leq x_{1} \leq 3 \\
N, & \text { if } & x_{1}<0
\end{array}\right.
$$

the time of commissioning:

$$
\mu_{E P}\left(x_{2}\right)=\left\{\begin{array}{llc}
S, & \text { if } & 0<x_{2} \leq 5 \\
M, & \text { if } & 2 \leq x_{2}<14 \\
B, & \text { if } & 6 \leq x_{2}<18 \\
V B & \text { if } & x_{2} \geq 15
\end{array}\right.
$$

the site for installation:

$$
\mu_{I L}\left(x_{3}\right)=\left\{\begin{array}{llc}
N H, & \text { if } & x_{3} \leq-0,4 \\
P N, & \text { if } & -0,4<x_{3} \leq 0,4 \\
N, & \text { if } & x_{3}>0,40
\end{array}\right.
$$

the schematic diagram of connections:

$$
\mu_{E S C}\left(x_{4}\right)=\left\{\begin{array}{llc}
N H, & \text { if } & x_{4} \leq-0,4 \\
P N, & \text { if } & -0,4<x_{4} \leq 0,4 \\
N, & \text { if } & x_{4}>0,40
\end{array}\right.
$$

the location in the system:

$$
\mu_{S L}\left(x_{5}\right)=\left\{\begin{array}{llr}
S I, & \text { if } & -1 \leq x_{5} \leq 0 \\
P N, & \text { if } & 0<x_{5} \leq 1
\end{array}\right.
$$

the controlled shunt reactor installation:

$$
\mu_{R P}\left(x_{6}\right)= \begin{cases}M P, & \text { if }-0,5 \leq x_{6} \leq 0 \\ P P, & \text { if }-0,5<x_{3} \leq 0,5 \\ P, & \text { if } \quad x_{3}>0,5\end{cases}
$$

After the fuzzy implication forms, fuzzy constraints, and membership functions had been determined, the output signals were formed based on the fuzzy approximation between the input and output vectors.

$$
\mu_{A, i}(x): X_{i} \rightarrow[0,1] \text {. }
$$
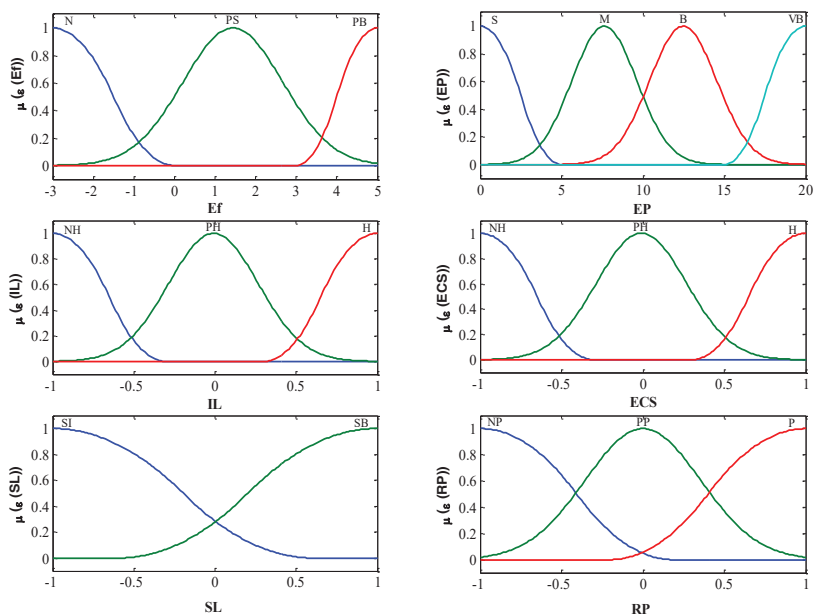

Fig. 1. Membership function of terms of linguistic variables. 
Table 2. Terms of linguistic variables, membership functions, and their parameters

\begin{tabular}{|c|c|c|}
\hline Term-subsets & $\begin{array}{l}\text { Membership } \\
\text { functions }\end{array}$ & Parameters \\
\hline \multicolumn{3}{|c|}{ Efficiency index, EI } \\
\hline Negative $(\mathrm{N})$ & $\mathrm{Zmf}$ & {$\left[\begin{array}{ll}-3 & 0\end{array}\right]$} \\
\hline Positive small (PS) & Gaussmf & {$\left[\begin{array}{lll}1.23 & 1.44\end{array}\right]$} \\
\hline Positive big (PB) & Smf & {$\left[\begin{array}{ll}3 & 5\end{array}\right]$} \\
\hline \multicolumn{3}{|c|}{ Commissioning period, EP } \\
\hline Small(S) & $\mathrm{Zmf}$ & {$\left[\begin{array}{ll}0 & 5\end{array}\right]$} \\
\hline Mean (M) & Gaussmf & {$\left[\begin{array}{ll}2 & 7.62\end{array}\right]$} \\
\hline $\operatorname{Big}(\mathrm{B})$ & Gaussmf & {$\left[\begin{array}{ll}2.07 & 12.47\end{array}\right]$} \\
\hline Very big (VB) & Smf & {$\left[\begin{array}{ll}14.97 & 20\end{array}\right]$} \\
\hline \multicolumn{3}{|c|}{ Installation sites, IL } \\
\hline No (NH) & $\mathrm{Zmf}$ & {$\left[\begin{array}{ll}-1 & -0.3\end{array}\right]$} \\
\hline $\begin{array}{l}\text { Partially available } \\
\text { (PH) }\end{array}$ & Gaussmf & {$\left[\begin{array}{ll}0.277 & -0.009\end{array}\right]$} \\
\hline Available $(\mathrm{H})$ & Smf & {$[0.31]$} \\
\hline \multicolumn{3}{|c|}{ Connection diagram, ECS } \\
\hline No $(\mathrm{NH})$ & Zmf & {$\left[\begin{array}{ll}-1 & -0.3\end{array}\right]$} \\
\hline $\begin{array}{l}\text { Partially available } \\
\text { (PH) }\end{array}$ & Gaussmf & {$\left[\begin{array}{ll}0.277 & -0.009\end{array}\right]$} \\
\hline Available (H) & Smf & {$[0.31]$} \\
\hline \multicolumn{3}{|c|}{ Locations in the system, $\mathrm{SL}$} \\
\hline Backbone. SI & $\mathrm{Zmf}$ & {$\left[\begin{array}{ll}-1 & 0.607\end{array}\right]$} \\
\hline Between systems. SB & Smf & {$\left[\begin{array}{ll}-0.6 & 1\end{array}\right]$} \\
\hline \multicolumn{3}{|c|}{ Controlled shunt reactor installation, RP } \\
\hline Do not install (MP) & Zmf & {$\left[\begin{array}{ll}-1 & 0.18\end{array}\right]$} \\
\hline Partially possible (PP) & Gaussmf & {$[0.350]$} \\
\hline Install (P) & Smf & {$\left[\begin{array}{ll}-0.2 & 1\end{array}\right]$} \\
\hline
\end{tabular}

The membership functions of input and output variables and their terms are shown in Fig.1, and their parameters are given in Table 2.

The fuzzy output mechanism consisting of 65 rules synthesized based on the Mamdani algorithm is shown in Fig.2.

The relationships between the indicated surfaces and output variables (CSR installation node), given the fuzzy constraints, are presented in Fig.4. As can be seen in Fig.4, the red parts of the surfaces describe positive solutions and in each case, they correspond to positive values of efficiency index. In other words, the reactor installation at

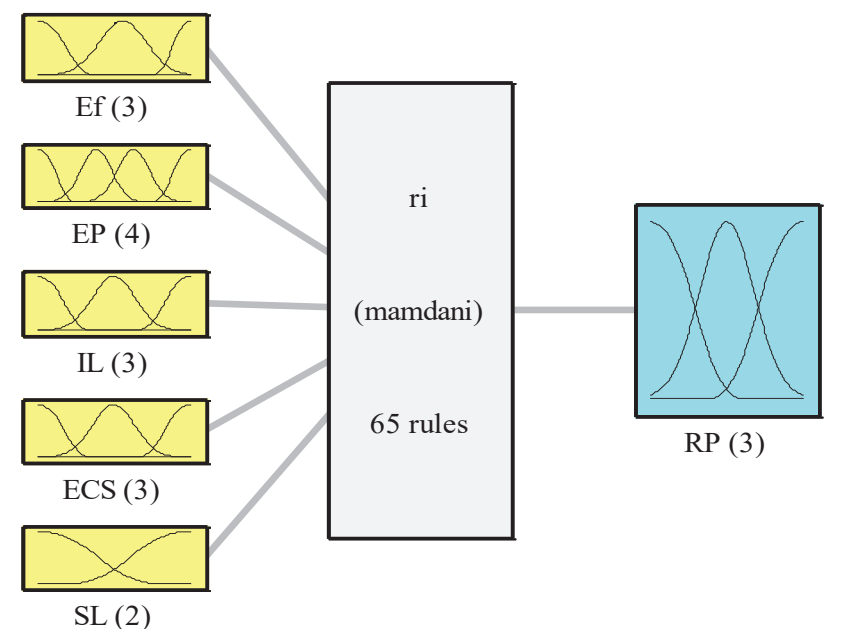

Fig.2. The fuzzy logic output mechanism.

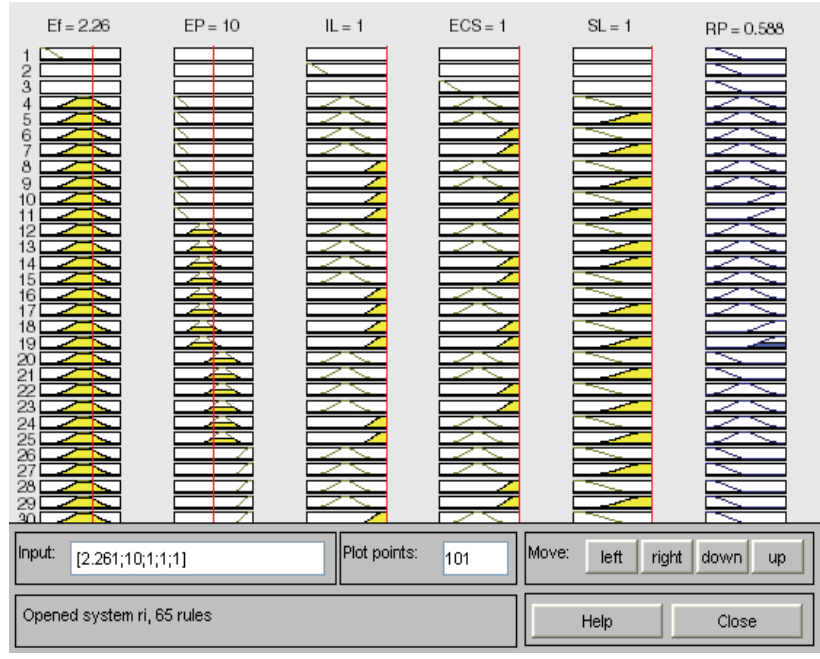

Fig. 3. A decision-making procedure segment.

the indicated nodes leads to both the reduction in voltage at other system-significant nodes and a decrease in active power losses in power transmission networks.

Table 3 presents the results of adjusting the priority nodes according to this procedure. Calculations were performed based on the ETAP software system considering the fuzzy constraints (3)-(8) [14].

As seen in the Table, the nodes meeting the $E_{e f, \Sigma}<0$ condition are not considered to be the priority ones and are not taken into account for the CSR installation.

Thus, in terms of these factors, the priority nodes are Goranboy SG, Janub ES, Yashma 330 kV, Imishli SS, and Khachmaz $330 \mathrm{kV}$. In this case, given the location in the system and the calculation results, we can initially accept the Yashma $330 \mathrm{kV}$ and $330 \mathrm{kV}$ Goranboy SG nodes. The schemes prove efficient and reliable because both nodes meet the condition $E_{e f, \Sigma}>0$ and, also, due to the ability to connect the reactor to busbar at the Yashma $330 \mathrm{kV}$ substation, the availability of a free node in a one-and-a-half breaker arrangement of the $330 \mathrm{kV}$ Goranboy switchgear, and the availability of appropriate sites for the reactor
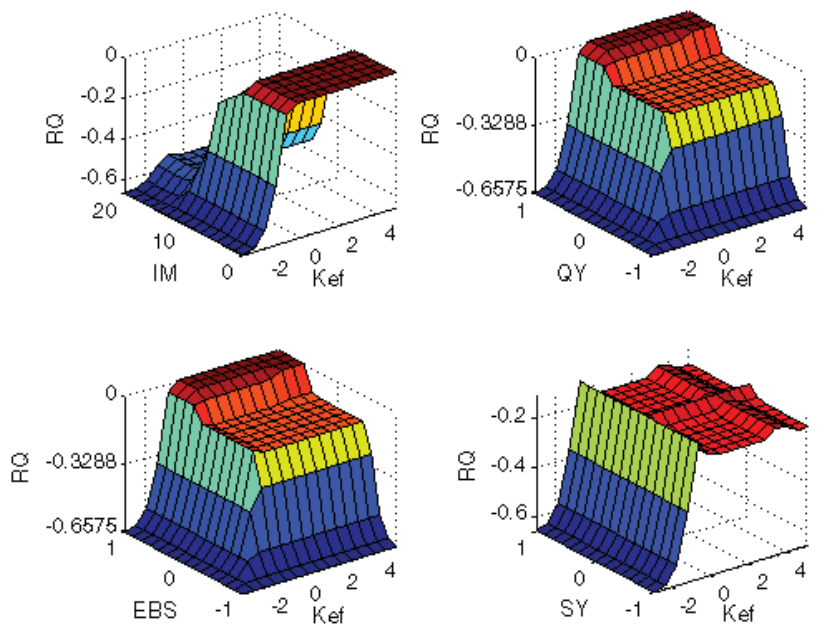

Fig. 4. Fuzzy surface relationships. 
Table 3. Efficiency index values for $330 \mathrm{kv}$ nodes.

\begin{tabular}{|c|c|c|c|c|c|c|c|c|c|c|}
\hline \multirow{2}{*}{$\begin{array}{l}\dot{0} \\
z \\
0 \\
0 \\
z\end{array}$} & \multirow[b]{2}{*}{ Node name } & \multicolumn{2}{|c|}{ Voltage, kV } & \multirow{2}{*}{ 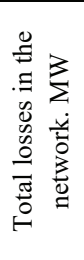 } & \multicolumn{2}{|c|}{$\begin{array}{c}\text { Absolute and } \\
\text { relative decrease in } \\
\text { total losses }\end{array}$} & \multicolumn{2}{|c|}{$\begin{array}{c}\text { Average absolute } \\
\text { and relative } \\
\text { voltage decrease }\end{array}$} & \multirow{2}{*}{$\begin{array}{l}\text { Efficiency } \\
\text { index } E_{e f}\end{array}$} & \multirow{2}{*}{$\begin{array}{c}\text { CSR } \\
\text { installati } \\
\text { on } \\
R P\end{array}$} \\
\hline & & $\begin{array}{l}\text { Bus voltage } \\
\text { before CSR } \\
\text { connection }\end{array}$ & $\begin{array}{c}\text { Average } \\
\text { voltage after } \\
\text { CSR } \\
\text { connection }\end{array}$ & & MW & $\%$ & $\mathrm{kV}$ & $\%$ & & \\
\hline 400 & Goranboy SG & 338.76 & 334.91 & 14.9 & 0.3 & 1.97 & 2.92 & 0.86 & 1.704 & 0.518 \\
\hline 201 & Janub PP & 346.53 & 334.66 & 14.6 & 0.6 & 3.94 & 3.17 & 0.94 & 3.701 & 0.508 \\
\hline 101 & Yashma 330 & 342.18 & 333.96 & 14.9 & 0.3 & 1.97 & 3.87 & 1.15 & 2.261 & 0.172 \\
\hline 280 & Imishli 330 & 344.27 & 333.86 & 15.0 & 0.2 & 1.32 & 3.97 & 1.18 & 1.548 & 0.015 \\
\hline 801 & Khachmaz 330 & 343.43 & 333.99 & 15.0 & 0.2 & 1.32 & 3.84 & 1.14 & 1.497 & 0.014 \\
\hline 333 & Agdjabedi 330 & 342.64 & 333.78 & 15.0 & 0.2 & 1.32 & 4.05 & 1.19 & 1.577 & 0.013 \\
\hline 456 & Samukh 330 & 328.74 & 335.98 & 15.6 & -0.4 & -2.63 & 1.85 & 0.55 & -1.443 & -0.434 \\
\hline 411 & Shamkir HPP & 331.01 & 336.13 & 15.4 & -0.2 & -1.32 & 1.70 & 0.50 & -0.663 & -0.536 \\
\hline 601 & Mini HPP & 339.44 & 335.55 & 14.7 & 0.5 & 3.29 & 2.41 & 0.71 & 2.349 & -0.551 \\
\hline 651 & AzES 330 & 339.23 & 335.55 & 14.7 & 0.5 & 3.29 & 2.28 & 0.68 & 2.219 & -0.551 \\
\hline 401 & Gandja330 & 329.82 & 335.79 & 15.5 & -0.3 & -1.97 & 2.04 & 0.60 & -1.190 & -0.558 \\
\hline 457 & GAZ 330 & 328.28 & 335.89 & 15.8 & -0.6 & -3.95 & 1.94 & 0.58 & -2.269 & -0.631 \\
\hline 502 & Agstafa 330 & 330.89 & 335.25 & 15.9 & -0.7 & -4.61 & 2.58 & 0.76 & -3.516 & -0.658 \\
\hline 39 & Absheron 330 & 344.38 & 334.23 & 14.5 & 0.7 & 4.61 & 3.60 & 1.07 & 4.912 & -0.658 \\
\hline
\end{tabular}

placement. It should be noted that the $330 \mathrm{kV}$ Yashma substation is very important for Azerbaijan's power system due to its location. The eastern part of Russia's power system is connected to the power system of Azerbaijan via the $330 \mathrm{kV}$ Derbend-Khachmaz PTL, which plays an important role in frequency regulation under extreme conditions. The installation of a controlled shunt reactor at this substation will have a special contribution to the increase in power system stability.

As can be seen in Table 1. the $330 \mathrm{kV}$ Goranboy ES buses and $330 \mathrm{kV}$ Imishli nodes can be considered to be candidates for the CSR installation, as the third node.

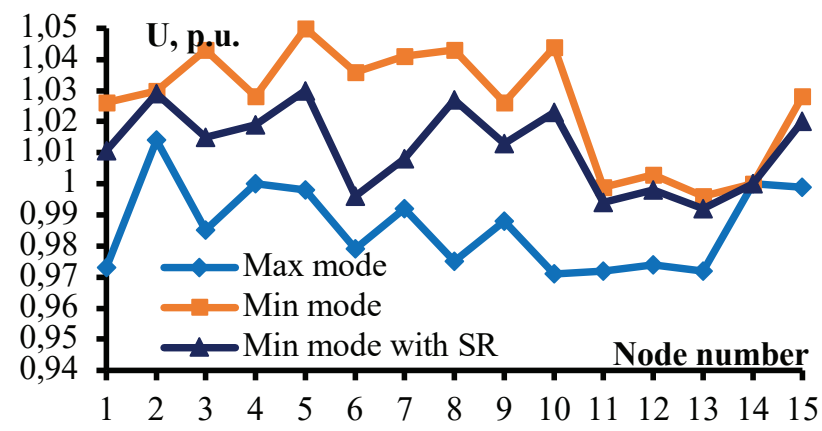

Fig.5.Voltage profiles at $330 \mathrm{kV}$ and $500 \mathrm{kV}$ nodes for normal operating conditions of the power system.

Table 4. Voltage variation limits at $500 \mathrm{kv}$ and $330 \mathrm{kv}$ nodes.

\begin{tabular}{ccccc}
\hline \hline Conditions & \multicolumn{2}{c}{ Load } & \multicolumn{2}{c}{ Voltage variation interval } \\
\hline & $\mathrm{P}$, & $\mathrm{Q}$, & $500 \mathrm{kV}$ & $330 \mathrm{kV}$ \\
\hline Maximum & 5613.9 & 3355.2 & $\begin{array}{c}(1.0- \\
1.014) \mathrm{U}_{\text {nom }}\end{array}$ & $\begin{array}{c}(0.972- \\
0.999) \mathrm{U}_{\text {nom }}\end{array}$ \\
\hline Minimum & 1684.2 & 1006.6 & $\begin{array}{c}(1.0- \\
1.03) \mathrm{U}_{\text {nom }}\end{array}$ & $\begin{array}{c}(0.996- \\
1.05) \mathrm{U}_{\text {nom }}\end{array}$ \\
\hline $\begin{array}{c}\text { Minimum after } \\
\text { reactor } \\
\text { connection }\end{array}$ & 1684.2 & 1006.6 & & $\begin{array}{c}(0.992- \\
1.03) \mathrm{U}_{\text {nom }}\end{array}$ \\
\hline \hline
\end{tabular}

\section{SIMULATION RESULTS}

To determine voltage levels at the power system nodes, one should make corresponding calculations for the maximum and minimum load conditions. The voltage profiles of some characteristic $330 \mathrm{kV}$ and 500 $\mathrm{kV}$ load nodes based on the calculations performed for the maximum and minimum load conditions in real power system schemes are shown in Fig.5.

It is worth noting that the maximum load conditions of the power system were formed according to the data obtained from the Prospective Development Department of the "AzSRDPPEI" LTD. The minimum load conditions were assumed to be $0.3 \mathrm{Pmax}$ (Pmax is the maximum active load of the power system).

Figure 5 shows that under the maximum load conditions $(\mathrm{Py}=5613.9 \mathrm{MW}, \mathrm{Qt}=3355.2 \mathrm{MVAr})$, the voltage at the $500 \mathrm{kV}$ nodes varies within the (1.0-1.014) Unom interval, at the $330 \mathrm{kV}$ nodes - within the (0.972-0.999) Unom interval. Under the minimum load conditions $(\mathrm{Py}=1684.2$ $\mathrm{MW}, \mathrm{Qt}=1006.6 \mathrm{MVAr})$, the voltage at the $500 \mathrm{kV}$ nodes varies within the (1.0-1.03) Unom interval, and at the 330 $\mathrm{kV}$ nodes - within the (0.996-1.05) Unom interval (Table 4). Thus, the voltage under the maximum and minimum load is within normal limits. At some nodes, the voltage is set to the upper limit.

In the light of the foregoing, the calculation was repeated for the minimum load conditions with a 180 MVAr shunt reactor connected to the $330 \mathrm{kV}$ Goranboy node, and a 100 MVAr reactor connected to the $330 \mathrm{kV}$ Yashma node. As can be seen, with the reactor connection, the voltage profiles in the case of the minimum load conditions improve and change within the range (0.9921.03) of Unom near the nominal value.

In the next stage, the calculations were made with the modeling of emergency conditions according to the criteria 

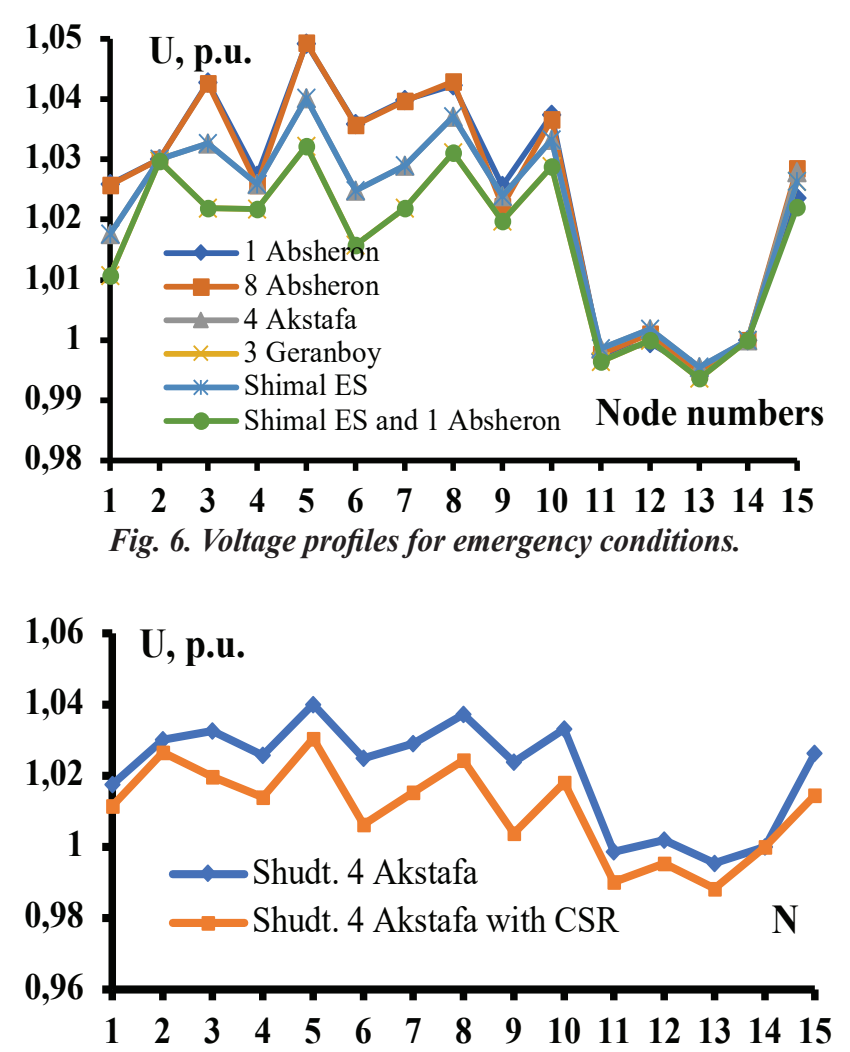

Fig.7. Voltage profiles after CSR connection and disconnection for the case of Agstafa-4 line shutdown

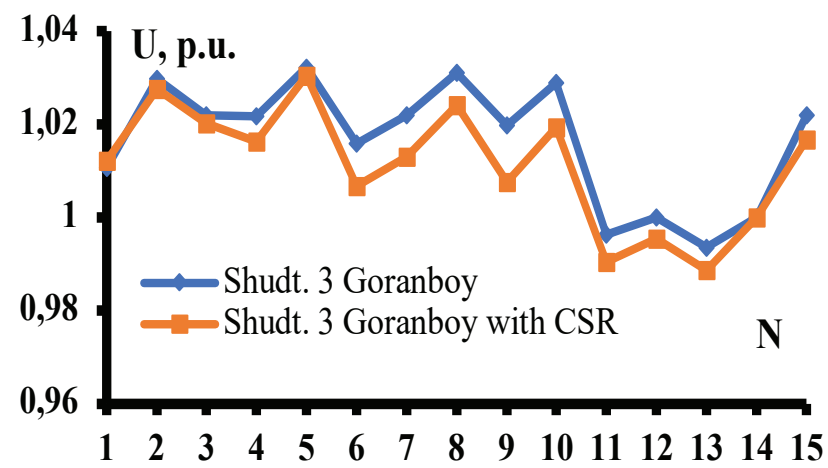

Fig.8. Voltage profiles after CSR connection and disconnection for the case of the Goranboy-3 line shutdown

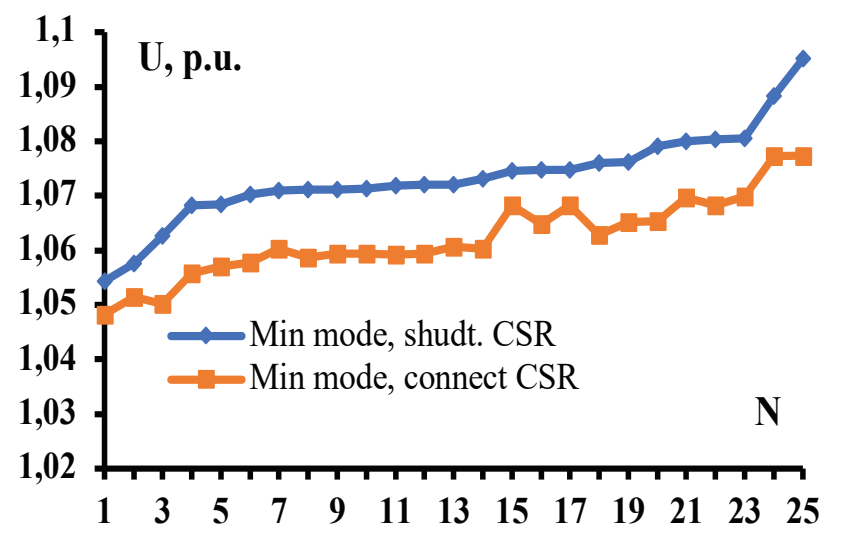

Fig. 9. Voltage profiles at $220 \mathrm{kV}$ nodes of the power system in the cases with and without the $330 \mathrm{kVCSR}$
$\mathrm{N}-1$ and $\mathrm{N}-2$. We considered the disconnection of lines Absheron-1, Absheron-8, Agstafa-4, Goranboy-3, and Shimal ES according to criterion $\mathrm{N}-1$, and the disconnection of lines Shimal ES and Absheron-1 according to criterion N-2.

Figure 6 shows the voltage profiles at the nodes based on the results of calculations performed according to the $\mathrm{N}-1$ criterion.

As seen in Fig.6, the model calculations for emergency conditions of the power system based on the $\mathrm{N}-1$ criterion indicate the voltage at the nodes within acceptable limits. The voltage at some nodes, for example, at node 5 (Janub ES), after the disconnection of Absheron-8, Agstafa-4, and Goranboy-3 lines reached the upper limit. The same conclusion can be drawn for the Imishli node. Based on this, the calculations were carried out for the case of shunt reactors connected to certain nodes under some of the considered emergency conditions (disconnection of the Agstafa-4 and Goranboy-3 lines).

Figures 7 and 8 show the voltage profiles for the cases of disconnection of Agstafa-4 and Goranboy-3 lines.

Figures 7 and 8 show that with the CSR connection, the voltage profiles relatively improve.

The above results are given for the case of the CSR maximum conditions. Bus voltage curves with the load change at the $220 \mathrm{kV}$ nodes of Yashma SS under the preset power values are presented in Fig.9.

Appropriate calculations for the minimum conditions were performed to study the effect of CSR connected to two $330 \mathrm{kV}$ nodes of the power system on the voltage at $220 \mathrm{kV}$ nodes. According to the calculations, the voltage at $220 \mathrm{kV}$ nodes is within the Unom range (1.054-1.095). In this connection, the placement of compensating devices at the $220 \mathrm{kV}$ nodes was considered.

Lines of the $220 \mathrm{kV}$ nodes generate a charging power of 327.6 MVAr. Voltage profiles obtained using the results of calculations done for the cases of the $330 \mathrm{kV}$ CSR connection and disconnection are presented in Fig.9. As seen in the Figure, the effects of the $330 \mathrm{kV}$ CSR are convex, and the voltage level is within the range set by the power quality standard [15].

\section{RESULTS OF THE REACTOR EFFICIENCY STUDY}

The effective operation involves stabilizing voltage in backbone electrical networks by RTU-120000/330 and RTU-180000/330 type shunt reactors, which are installed at $330 \mathrm{kV}$ Yashma SS and $330 \mathrm{kV}$ Goranboy switchgear. The calculations were performed for different load conditions of the power system in a range of reactive power regulation $0-100 \%$.

If the shunt reactor is controlled, then the crisp voltage regulation is possible within the range of its voltage regulation with the load change. The calculations were performed to demonstrate it. They confirmed the crisp voltage regulation effect during the load rise in the case of the 100 MVAr CSR placement at the $330 \mathrm{kV}$ Yashma SS 


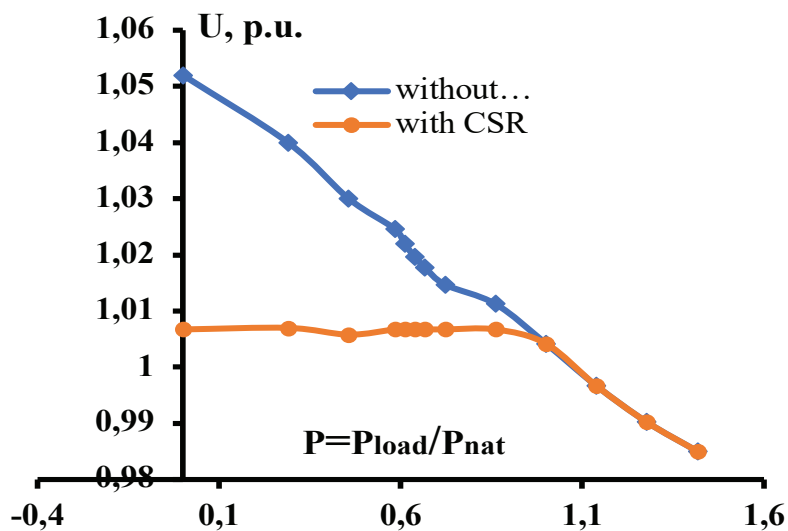

Fig.10. $330 \mathrm{kV}$ bus voltage curves of Yashma SS in the cases with and without CSR

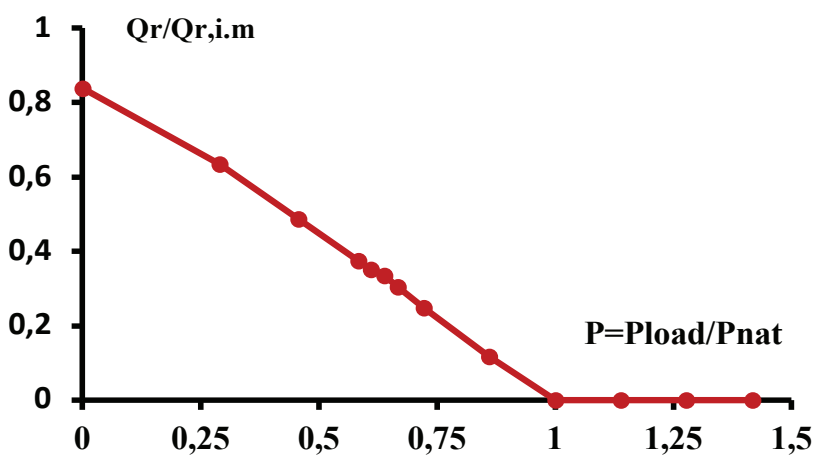

Fig.11. Power curves of the CSR maintaining stable voltage/ load change at $220 \mathrm{kV}$ buses of Yashma SS

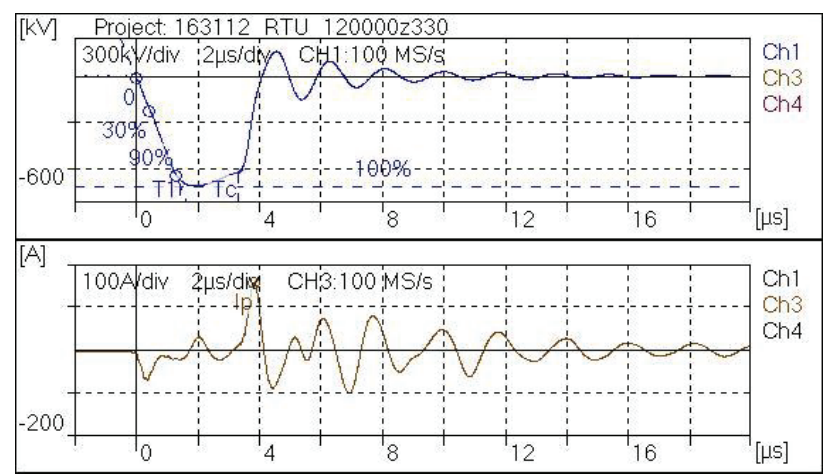

a)
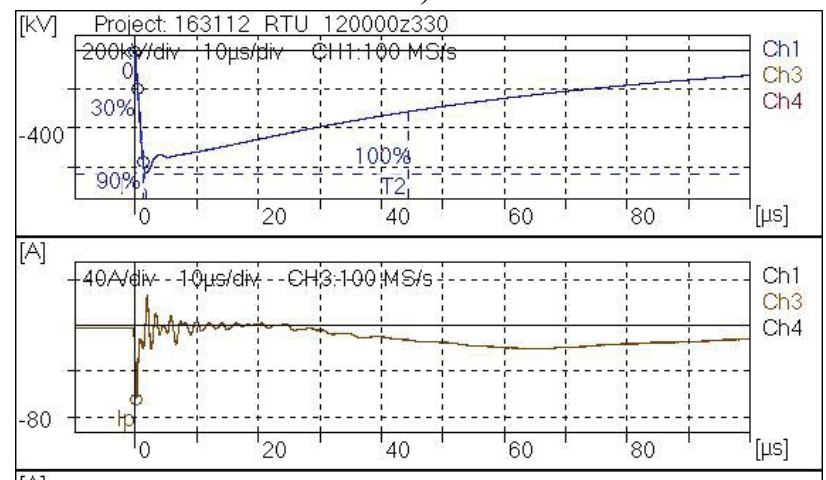

b)

Fig.12. CSR's lightning impulse voltage test curves and voltage curves were constructed on their basis (Fig.10).

As seen in Fig.10, during an increase in active power load in the 0-300 MW range and reactive load in the 0-270 MVAr range at the $220 \mathrm{kV}$ side of the substation, the voltage in the case without CSR reduces up to 0.96 Unom. In the case with CSR, at the expense of crisp regulation (reduction) of its power, the voltage at $330 \mathrm{kV}$ bus, regulated practically crisply, is maintained stable at value 1.002 Unom. Only afterward, during subsequent load rises, because the line requires a reactive power, the voltage reduces and, if necessary, in this case, additional regulators should be used. At the same time, Fig. 10 shows that if the SR power is not regulated (uncontrolled SR), then bus voltages are not stable and sharply reduce with the load increase.

The power curves of CSR, which stabilizes the voltage with the load increase at $220 \mathrm{kV}$ bus of Yashma SS, are presented in Fig.11. Figures 10 and 11 show that at a load increase, the CSR power crisply regulated in a 100 -0 MVAr range keeps the $330 \mathrm{kV}$ bus voltage stable in allowable limits.

Tests for the reactors of the considered types were performed at manufacturing plants. Reactors' lightning impulse voltage test curves (voltage and current curves) are presented in Figs. 12 a.b.

Fig.12. CSR's lightning impulse voltage test curves

Thus, the above results confirm the efficiency and necessity of CSR for charging power compensation and voltage regulation.

\section{CONCLUSIONS}

1. The paper proposes a procedure for selecting and placing the controlled shunt reactors at $330 \mathrm{kV}$ nodes with fuzzy constraints to control the reactive power flows in the power system.

2. Based on the developed procedure, the priority nodes for the CSR placement in the Azerenergy system were identified. The calculations of operating conditions with the CSR placed at these nodes were performed. The findings have confirmed a significant improvement in voltage profiles at the nodes.

3. High impulse voltage test curves, which confirm voltage stability at high-voltage buses within the CSR regulation range and define the operating zone, were constructed under laboratory conditions. The performed tests confirmed the reliable operation of the CSR.

\section{REFERENCES}

[1] Tukhvatullin M.M., IvekeyevV.S., Lozhkin I.A., Urmanova F.F. Analysis of modern FACTS devices used for the increase of efficiency of operation of power grids of Russia. Electrotechnical Systems and Complexes. No. 3 (28). 2015, pp.41-46.

[2] Thatarad S., Kiatiyuth K. Load Alleviation in Transmission System by Using Phase Shifting Transformer. 2018 International Electrical Engineering Congress (IEECON). 7-9 March, 2018, Krabi. Thailand. 
[3] Dolgopolov A.G. Bias-controlled shunt reactors. Operation speed issues. News of Electrical Engineering. No.4 (64). 2010.

[4] Bryantsev M.A., Lurie A.I., Spiridonov D.Y. Results of the introduction of bias-controlled shunt reactors in 110-500 kV networks. Electro. No.3. 2006, pp. 25-31.

[5] Bias-controlled electric reactors/ed. by Bryantsev A.M. M.: ZNAK. 2010, p. 288.

[6] Kochkin V.I., Nechaev O. P. Application of static reactive power compensators in electrical networks of power systems and enterprises. M.: ENAS Publishing Group. 2002, p. 248.

[7] Alexandrov G.N. Supervoltage installations and environmental protection. L.: Energoatomizdat. 1989, p. 360.

[8] Controlled bias electric reactors/ ed. by Bryantsev A. M.: ZNAK, 2010, p. 288.

[9] STO 70238424.29.240.99.003-2011. Controlled devices for reactive power compensation, voltage and power flow regulation, conditions of creation. Norms and requirements. Approved and enforced by order of NP "INVEL" dated November 1, 2011, No. 109/4. Moscow. 2011, p. 32.

[10] Hashimov A.M., Guliyev H.B., Babaeva A.R. Selection and placement of compensating devices of the excess reactive power in high-voltage electrical networks. Problems of Power Engineering. No.1. 2019, pp. 3-12.

[11] Nazarova Y.S. Development of a methodology for choosing installation locations for transverse reactive power compensation devices in 330-500 kV networks. Ph.D. thesis, Ivanovo, 2012, p. 24.

[12] Elrazaz Z., Al-Ohaly A.A. Selection of shunt reactor locations to enhance system transient stability at light load operation. Electric Machines \& Power Systems. 17:3. pp. 221-231.

[13] Dolgopolov A.G., Condratenko D.V., Ucolov S.V., Postolati V.M. Reactoare controlate shuntate pentru retele electrice. Problemele Energeticii Regionale. 3(17). 2011, pp.1-21.

[14] Hashimov A.M., Guliyev H.B., Babayeva A.R. Managing shunt reactors in accordance to fuzzy controllers for stabilization of voltage in high tension tire-cover. International Journal on Technical and Physical Problems of Engineering (IJTPE). Issue 30, Vol. 9, No. 1, 2017, pp.18-22.

[15] Hashimov A.M., Guliev H.B., Babayeva A.R. Multipole fuzzy logic controller to improve the control of shunt reactors//Electricity. No. 6. 2019, pp. 26-32.

[16] Shtovba S.D. Designing fuzzy systems using MATLAB/ Moscow: Hotline-Telecom. 2007, p. 288.

[17] ETAP. Power Station 7.0, User Guide, Volume II, Analysis Modules. Operation Technology. Inc. Registered to ISO 9001. Certification No. A3147. 2002, 3829 p.

[18] Electric power. Electromagnetic compatibility of technical facilities. Electric power quality standards in general-purpose power supply systems: GOST 32144-2013. Moscow: Standardinform. 2014, p.18.

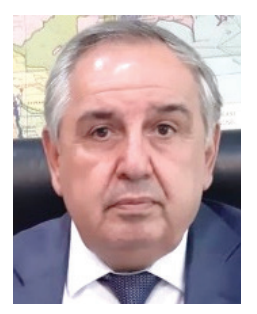

Arif M. Hashimov is a Professor of Power Engineering (1993); Chief Editor of Scientific Journal "Power Engineering Problems" since 2000; Director of Institute of Physics of Azerbaijan National Academy of Sciences (Baku. Azerbaijan) in 2002 -2009; Academician of Azerbaijan National Academy of Sciences and its First Vice-President (2007-2013). He is a laureate of Azerbaijan State Prize (1978); Honored Scientist of Azerbaijan (2005); Cochairman of International Conferences on "Technical and Physical Problems of Power Engineering" (ICTPE) and Editor in Chief of International Journal "Technical and Physical Problems of Engineering" (IJTPE). Now he is a Senior Consultant in the JSC "Azerenerji", Baku, Azerbaijan. His research areas are the theory of non-linear electrical networks with distributed parameters, neutral earthing and ferroresonant processes, alternative energy sources, high-voltage physics and techniques, and electrical physics. He is the authors of 350 articles, 5 monographs, , and patents.

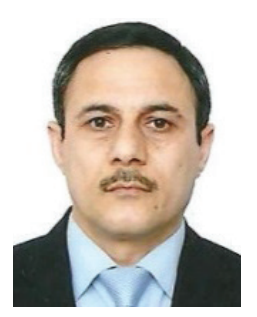

Huseyngulu B. Guliyev M.Sc., Ph.D., is a Lead Scientific Researcher, Head of Department of Power System Operating Conditions and the Problems of their Control in Azerbaijan ScientificResearch and Design-Prospecting Power Engineering Institute (Baku, Azerbaijan). Currently, he is an Associate Professor of the Automation and Control Department in Azerbaijan Technical University (Baku, Azerbaijan). $\mathrm{He}$ has more than 200 published articles, and 3 patents. His research interests are power systems operation and control, distributed generation systems, application of artificial intelligence to power system control design, and power quality. 
Aytek R. Babayeva graduated from Azerbaijan State Oil Academy, Power Engineering Department (Baku, Azerbaijan) in 2000. She received the $\mathrm{Ph} . \mathrm{D}$. degree in 2004. She is currently with the Research Laboratory of High Voltage in Power Industry and is Head of the Sector in Higher Certification Commission (Baku, Azer $\neg$ baijan). The area of her research interests is monitoring of arresters in Azerbaijan to improve their efficiency and reliability.

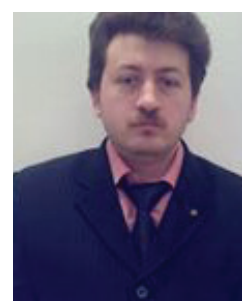

Ibrahimov Famil Shamil graduated from the Azerbaijan State Oil Academy, Department of Energy, majoring in Electrical Engineering and Systems in 2000. He is currently a leading engineer in the Department of Regulation and Control of Power Systems of Azerbaijan Scientific-Research and Design-Prospecting Power Engineering Institute, and a post-graduate student of the Department. 